\title{
O filme Medianeras sob a perspectiva da reificação e o ensino de Filosofia
}

\author{
Gilberto Miranda Jr. ${ }^{73}$
}

Resumo: O presente artigo tem por objetivo analisar a produção cinematográfica Medianeras - Buenos Aires na era do amor virtual sob a perspectiva do conceito de Reificação de György Lukács, problematizando transversalmente os protestos urbanos do início do século XXI e a vida urbana na contemporaneidade. Em seguida irá problematizar o uso de filmes no ensino de Filosofia, sua pertinência enquanto ferramenta de ensinoaprendizagem e o sentido da transversalidade como campo de atuação do ensino de Filosofia no Ensino Médio a partir da Lei de Diretrizes de Base $\mathbf{n}^{\mathbf{o}}$ 9394/96.

Palavras-Chave: Reificação, Cinema, Filosofia.

\section{The film Medianeras from a perspective of reification and the teaching of philosophy}

Abstract: This article aims to analyze the film production Medianeras - Buenos Aires na era do amor virtual from the perspective of György Lukács' concept of Reification, cross-sectionalizing urban protests of the early twenty-first century and urban life in contemporary times. Then, it will discuss the usage of film in teaching philosophy, its relevance as a teaching-learning tool and its sense of transversality as a field of activity of teaching philosophy in high school from the LDB/96.

Key Words: Reification, Cinema, Philosophy.

Submetido em: novembro de 2015.

Aprovado em: janeiro de 2016.

\section{Introdução}

Na década de 1970, segundo The Economist, o mapa da urbanização no mundo apontava para $63 \%$ de ocupação da área rural contra $1,5 \%$ de ocupação nas megacidades, sendo que os $35,5 \%$ restantes se espalhavam em cidades de pequeno, médio e grande porte. A proporção, portanto, era de $63 \%$ para $37 \%$ a favor das áreas rurais. Em 2010, essa proporção mudou para 51,6\% contra 48,4\% a favor da área urbana, com uma concentração de 5,3\% das pessoas (quatro vezes mais que em 70) nas megacidades. A projeção da urbanização para 2030, segundo o site Archdaily(GAETE, 2015), é a de que na área rural se concentre $40 \%$ da população e que as megacidades concentrem cerca de 8,6\% em, pelo menos, 41 megacidades espalhadas pelo mundo, sendo 29 asiáticas.

\footnotetext{
73 Graduado em Filosofia Centro Universitário Claretiano. Membro do Centro de Estudos em Filosofia da Universidade Federal Vale do Jequitinhonha e Mucuri -UFVJM. E mail:
} 
Além do movimento tradicional que tende do rural para o urbano, as cidades se caracterizam por movimentações próprias inter-regionais, intra-regionais e a chamada mobilidade pendular (commuting) e sazonal, segundo CUNHA (2005). Mas a questão mais problemática e que é foco do presente trabalho são os movimentos internos da cidade e de que forma esses movimentos, voluntários, espontâneos ou não, afetam e interferem nas relações sociais entre os indivíduos e na própria formação da subjetividade dos moradores das cidades, além, claro, da própria configuração das cidades em que esses indivíduos moram, vivem ou transitam.

É importante lembrar o ano de 2013 no Brasil.Nesse ano, em junho, a questão sobre a mobilidade urbana ganha relevo e mais de um milhão de pessoas saem às ruas em protesto em cerca de 388 cidades brasileiras. Um mês antes milhares haviam protestado nas principais ruas deIstambul, na Turquia, a partir da revolta com um projeto de reurbanização que transformaria o espaço verde do Parque TaksimGezi em um shopping center com uma Mesquita (BBC BRASIL, 2013). Assim como no Brasil, a truculência policial e a repressão a todo tipo de manifestação urbana autêntica, ao invés de arrefecer, catalisou a insatisfação geral e tomou proporções inimagináveis, pegando o governo, a mídia e o restante da população de espanto. No Brasil, a generalização dos protestos arregimentou pessoas insuspeitas que nunca havia protestado antes, mas que viram ali, no calor do conflito, sua voz fazendo coro a uma insatisfação silenciosa até então contra a deterioração da vida urbana através do fracasso dos serviços públicos, da saúde, da educação, da repressão policial, da corrupção do poder e dos estratosféricos gastos públicos em megaeventos como a Copa do Mundo e as Olimpíadas, obras que favoreceram escandalosamente empreiteiras suspeitas.

Essas rebeldias e protestos, com a marcante característica de nascerem dentro da urbe e do espaço planejado e direcionado ao fluxo financeiro e do mercado - a despeito de nos parecer um caos para habitação e relacionamentos - não se restringiram apenas a esses dois exemplos. Sejam por quais motivos, diretos ou indiretos, em vários casos muito diferentes, assistimos nessa primeira e início de segunda década do séc. XXI diversas rebeliões urbanas: cidades gregas e espanholas, Londres, Estocolmo, subúrbios parisienses, o movimento 'Occupy' no ocidente, Túnis, Egito, Síria, Bósnia, Ucrânia, etc. No entanto, segundo HARVEY (2015), nada disso deveria surpreender:

A urbanização tem, cada vez mais,constituído um sítio primário de infindável acumulação de capital que administra suas próprias formas de barbárie e violência sobre populações inteiras em nome do lucro. A urbanização se 
tornou o centro de atividades econômicas avassaladoras em escala planetária nunca antes vistas na história da humanidade.(HERVEY, 2015)

Apesar do cenário que se desenha nessa introdução, a maioria da população não se dá conta do que ocorre nas cidades e no mundo urbano. Eles vivem suas vidas a partir de suas razões instrumentalizadas, constrangidos pelas demandas do sistema e alienando-se compulsoriamente para atender necessidades que não são as suas, mas convencidos de que são. Solidão, palavra tão desgastada, passou a fazer parte do cotidiano dessas pessoas que vivem em meio a um formigueiro de gente anônima e afastada a um palmo de distância, sejam circunscritos na alienação que promovem a favor de seus interesses vendidos ou isolados em seus smatphones e Ipods. Não é nada raro, hoje em dia, vermos casais, amigos, pais e filhos sentados de frente para o outro, mas absortos em seus celulares, seja entretendo a si mesmos com jogos ou conversando com pessoas em outras localidades. E pior, já está deixando de ser bizarro.

Não pode ser desvinculado do processo de urbanização o uso e a concentração da tecnologia. Essa, por sua vez, feita pelo homem o domina e o modifica, assim como a própria cidade, criação humana e criadora humana, conforme nos define Robert Park:

(...) [a cidade é] a mais consistente e, no geral, a mais bem-sucedida tentativa do homem de refazer o mundo onde vive de acordo com o desejo de seu coração. Porém, se a cidade é o mundo que o homem criou, então é nesse mundo que de agora em diante ele está condenado a viver. Assim, indiretamente, e sem nenhuma ideia clara da natureza de sua tarefa, ao fazer a cidade, o homem refez a si mesmo. (PARK, R. apud HARVEY, 2013, p. 34)

Harvey, quando cita Park nesse trecho, argumenta que, concordando que a cidade deva refletir os desejos de nossos corações, aliado ao fato de que ao fazê-la também nos fazemos enquanto humanos, precisamos estar atentos continuamente com o que estamos a fazer de nós: "Se descobrimos que nossa vida se tornou muito estressante, alienante, simplesmente desconfortável ou sem motivação, então temos o direito de mudar de rumo e buscar refazê-lo segundo outra imagem e através da construção de um tipo de cidade qualitativamente diferente" (HARVEY, 2013, p. 35). E complementa: "Temos, em resumo, sido refeitos muitas vezes sem sabermos como ou por que" (Idem).

A que se pode atribuir, então, esse estado de coisas e a submissão acrítica a uma vida constrangida por interesses alheios a quem, de fato, vive nas cidades? É o que tentaremos responder ou, ao menos articular, com base no filme Medianeras de Gustavo Taretto (2011), que narra uma bela história de amor entre duas pessoas que vivem e se desencontram na cidade de Buenos Aires, Argentina. A história acontece em meio a 
todas essas características urbanas que fizemos menção nesta introdução. A análise do filme será feita sob a luz do conceito de Lukács (2003) de Reificação; fenômeno pelo qual a subjetividade assume o campo de referência das relações materiais nas quais a vida é submetida na atual sociedade de mercadorias. Em seguida procuraremos articular o ensino da Filosofia na utilização de produção cinematográfica sob a metodologia utilizada no próprio artigo: problematização do cotidiano de forma transversal através de conceitos filosóficos que podem ser exemplificados no filme.

\section{Reificação em Lukács}

György Lukács foi um filósofo húngaro nascido em Budapeste em 1885 e falecido em 1971 de grande importância no século XX. Ironicamente nascido filho de banqueiro, tornar-se-ia um dos grandes críticos do capitalismo do sec. $\mathrm{XX}$ fortemente influenciado pelas ideias de Marx, Rosa Luxemburgo e outros autores do universo da esquerda mundial. Por sua vez influencia grandes nomes como Adorno, Benjamin, Mannheim, Sartre, Merleau-Ponty entre outros (PINASSE e LESSA, 2002).

O conceito de Reificação foi cunhado por Lukács em seu livro História $e$ Consciência de Classe, publicado em 1923 e se constituindo em um dos livros mais lidos do sec. XX. Seu intento é ampliar e responder aos efeitos da Alienação e do Fetichismo da Mercadoria (conceitos de Marx), na medida em que o problema da sociedade de mercadoria sai da esfera da produção e passa, na relação mercantil e na formação das cidades, a constituir o "protótipo de todas as formas de objetividade e de todas as suas formas correspondentes de subjetividade na sociedade burguesa" (LUKÁCS, 2003, p. 193). Através da Reificação, Lukács chama a atenção para os problemas fundamentais que resultam do caráter fetichista da mercadoria, tanto de forma objetiva quanto do comportamento do sujeito submetido a esse caráter:

\footnotetext{
(...) o que importa aqui é saber em que medida a troca de mercadorias e suas consequências estruturais são capazes de influenciar toda a vida exterior e interior da sociedade. Portanto, a extensão da troca mercantil como forma dominante do metabolismo de uma sociedade não pode ser tratada como uma simples questão quantitativa - conforme os hábitos modernos de pensamento, já reificados sob a influência da forma mercantil dominante. A diferença entre uma sociedade em que a forma mercantil é adominante que influencia decisivamente todas as manifestações da vida e um sociedade em que ela aprece apenas episodicamente é, antes, uma diferença qualitativa. (LUKÁCS, 2003, p. 195)
}

Lukács argumenta que Marx já havia precisado essa diferença na medida em que as trocas dos excedentes de produção em sociedades pré-industriais ainda carregavam 
no valor de troca uma forma dependente do valor de uso em seu aspecto fundamental. Somente quanto a produção se tornou exclusivamente para a troca (ou seja, se tornaram mercadorias), tornando-se independentes do valor de uso e passando a representar somente sua transformação em dinheiro, foi que se tornou fetiche e passou a estabelecer no seio da sociedade uma transformação efetiva nas manifestações vitais, passando a "remodelar tais manifestações à sua própria imagem" (Ibidem, p. 196). O fetiche da mecadoria se dá pela percepção do homem que produz que o fruto daquilo que faz lhe escapa totalmente e adquire leis próprias que independem dele, que é o responsável por sua existência. Ao mesmo tempo em que ele se reconhece naquilo que faz, o seu caráter objetivo na forma de mercadoria foge totalmente de sua alçada e controle, sequer há qualquer tipo de posse ou propriedade sobre aquilo, denunciando o quanto ele é alienado daquilo e naquilo que faz. A mercadoria adquire um caráter fantasmagórico, enfeitiçante, revestindo-se de um misticismo inebriante.

A grande questão é que a mercadoria no capitalismo, de uma das formas possíveis que comporiao metabilismo social, passa a ser a única forma, a forma dominante e universal pela qual a sociedade se relaciona e se expressa em toda sua dinâmica. Ou seja, passou a constituir como que metafisicamente as relações a partir de seu caráter enfeitiçante e alientante. Constata-se, portanto, que:

\section{(...) o trabalho abstrato (...) que existe ao mesmo tempo como produto e condição da produção capitalista, surge apenas no curso do desenvolvimento desta e, portanto, somente no curso dessa evolução ele se torna uma categoria social que influencia de maneira decisiva a forma de objetivação tanto dos objetos como dos sujeitos da sociedade emergente, de sua relação com a natureza, das relações dos homens entre si que nela são possíveis. (LUKÁCS, 2003, p. 200-201)}

A estética fantasmagórica da mercadoria e sua expressão nas relações mercantis subsumiram o campo ético das relações na cidade, coisificando e isolando sistematicamente as pessoas. A própria cidade, criada fundamentalmente para facilitar os fluxos e controles do excedente de produção da zona rural e facilitar os negócios, tornam-se locais de moradia daqueles que tem seu trabalho nessa nova modalidade desprendida do processo produtivo primário, mas dependente totalmente dele: o terceiro setor. Hodiernamente, conforme denúncia de Harvey, as cidades também se tornam locais de exploração e de acumulação de capital, substituindo sua função de moradia por especulação imobiliária e, com isso, confinando as pessoas em locais insalubres que reforçam sua coisificação e distanciamento, paradoxalmente, 'a um palmo'. 


\title{
O Filme Medianeras - Buenos Aires na era do amor virtual
}

\begin{abstract}
Buenos Aires cresce descontrolada e imperfeita. É uma cidade super povoada em um país deserto. Uma cidade onde se erguem milhares e milhares de edifícios se nenhum critério. Ao lado de um muito alto tem um muito baixo. Ao lado de um racionalista tem um irracional. Ao lado de um em estilo francês tem outro sem nenhum estilo. Provavelmente essas irregularidades nos refletem perfeitamente. Irregularidades estéticas e éticas. Esses edifícios que se sucedem sem nenhuma lógica, demonstram uma falta total de planejamento. Exatamente igual a nossa vida, que a fazemos sem saber como queremos que fique. Vivemos como quem está de passagem porr Buenos Aires. Somos criadores da cultura do inquilino. (Personagem Martin, fala inicial in Medianeras - Buenos Aires na Era do Amor Virtual, 2011)
\end{abstract}

O filme se centraliza na vida de duas personagens: Martin e Mariana. Ambos vivem na metrópole de Buenos Aires habitando o mesmo quarteirão sem nunca terem se encontrado. Dessa forma o filme retrata as sensações de solidão e de individualismo presentes em cidades como Buenos Aires, construídas sem planejamento, onde um prédio dá lugar a outro e as pessoas passam a habitar uma grande 'selva de pedras', morando em apartamentos tão pequenos e sem ar que mais parecem 'caixas de sapato'. Apesar do aparente caos e irregularidades, é possível perceber a lógica construtiva da cidade. Mais do que isso, os efeitos dessa lógica. Martin continua sua reflexão:

\footnotetext{
Os edifícios, como toda coisa pensada pelo homem, servem para diferenciar uns dos outros. Existe a frente e existe o fundo. Andares altos e baixos. Os privilegiados são identificados pela letra A, excepcionalmente a B. Quanto mais progresso no abecedário, menos categoria tem o apartamento. (...) Estou convencido que as separações, os divórcios, a violência familiar, o excesso de canais a cabo, a falta de comunicação, a falta de desejo, a agonia, a depressão, os suicídios, as neuroses, os ataques de pânico, a obesidade, as contraturas, a insegurança, a hipocondria, o estresse e o sedentarismo são responsabilidade dos arquitetos e empresários da construção. Desses males, salvo o suicídio, todos me acometem. (Idem)
}

O texto do filme reflete narrativas, falas e pensamentos deste dois sujeitos que expressam seus conflitos existenciais e de suas relações num contexto espacial notadamente propício ao distanciamento entre as pessoas, à impessoalidade e à solidão. Duas personagens extremamente solitárias e que vivem em um pequeno apartamento dos grandes edifícios que possuem muito mais paredes que janelas - medianeiras: paredes sem utilidade, que não possuem janelas e que o mercado as utiliza transformando-as em cenários de grandes propagandas de diversos produtos. Suprimem-se as possíveis relações pela estética do mercado e das necessidades do comércio.

Martin é um paciente de síndrome de pânico em recuperação. Seu tratamento 
para perder o medo da cidade onde vive é sair para tirar fotos, o que para ele é um jeito de redescobrir a cidade e as pessoas. Seu deslocamento é sempre a pé, e embora passe pelas mesmas ruas de Mariana, nunca se encontram. Mariana é arquiteta há dois anos, mas nunca construiu nada e nem foi bem com outras construções que não eram dela. Recém-separada de uma relação de quatro anos, sente-se apática e estacionada na vida, trabalhando em uma loja de roupas como vitrinista. Costuma ir ao planetário, cuja arquitetura admira, para sentir-se parte de um todo eterno, embora uma ínfima parte. Possui um livro Onde está Wally desde os 14 anos e que é a origem de sua fobia por multidões e da angústia em saber que é alguém perdido entre milhões. Há uma das páginas que ela nunca conseguiu resolver, que é, justamente, 'Wally na cidade’: “Então me pergunto, se mesmo sabendo quem eu procuro, não consigo achar, como vou encontrar quem procuro se nem sei como é?” (Mariana in Medianeras, 2011).

Martin encontra sua vida real no mundo virtual da internet. Ali ele tem tudo o que precisa: compra comida, roupas, materiais de necessidades básicas, pesquisa, aprende e, por fim, relaciona-se. Ele procura encontrar uma mulher com a qual possa se relacionar através do contato virtual. Mas na vida real tudo é muito diferente do que o virtual apresenta.Martin e Mariana têm as mesmas necessidades, vivem os mesmos conflitos e moram um do lado do outro, no mesmo quarteirão. A história passa o tempo todo focalizada na distância entre os dois que, embora sejam vizinhos, pela dinâmica da cidade, pela forma como ela é feita e construída, os encontros possíveis entre os dois não geram nenhuma perspectiva de aproximação.

Como filme, de acordo com a intenção do diretor, o acaso vem para formalizar um encontro que teria tudo para não acontecer. De repente Wally é Martin, visto na rua lá embaixo por Mariana que está à janela. Há um reconhecimento no meio de tanto estranhamento revelado ao longo das diversas cenas de uma cidade caótica para as pessoas, mas propícia à exploração do capital;cidade onde as pessoas parecem formigas: andando aos montes, alvoraçadas e apressadas pelo tempo escasso da cidade e de seus afazeres. Neste encontro tudo faz sentido para eles, antes extremamente solitários e vazios. Há identidade e um reconhecimento mútuo que possibilita a construção de uma relação. Algo que se duvidava existir.

Obviamente não é o final da maioria das pessoas que vive hoje nas cidades, o que nos faz trazer novamente David Harvey sobre essa questão. A crítica de Harvey centra-se em como a urbanização tornou-se mais uma das faces do capitalismo como sistema de produção. $\mathrm{O}$ direito às cidades está sendo sequestrado pela sede de negócios 
e as moradias não existem mais para pessoas morarem e conviverem, mas para especulação do mercado imobiliário fazendo a criação de sobre-valor ser contínua:

\begin{abstract}
Na visão de Harvey, esse processo de modificação no ambiente urbano é uma 'miríade de meios' (p. 66) para a reprodução do capital. As classes detentoras do poder econômico comandam o processo urbano. E as implicações dessa dominação não estão apenas sobre os aspectos de administração governamental e poderio do Estado com estruturas territoriais, mas sobre populações inteiras - alterando seus estilos de vida, possibilidade de trabalho, valores políticos e culturais e, até mesmo, concepções mentais do mundo. (BESSA, 2014, p. 214)
\end{abstract}

Taretto em Medianeras - Buenos Aires na Era do Amor Virtual, (2011) mostra isso de uma maneira que podemos perceber humor entre encontros e desencontros de pessoas que, na verdade, estão alheias ou subsumidas na desumanização compulsória de um sistema que se apropria da cidade e da vida através da reificação. Podemos entender que Mariana e Martin deram sorte, mas que em geral as pessoas vão desenvolvendo seus isolamentos de forma cada vez mais intensa.

\title{
O Ensino da Filosofia
}

Há um dilema implícito ao ensino de Filosofia no Ensino Médio o qual se centra na apreensão dos conceitos desenvolvidos ao longo da História da Filosofia enquanto ferramenta para um pensar filosófico em contraponto à ideia de que seja mais necessária a discussão de situações-problema do cotidiano do aluno como horizonte do ensino para desenvolver seu pensamento crítico e reflexivo. É importante salientar que não poderia haver ensino de Filosofia sem problemas filosóficos a serem refletidos e considerados. O uso de um filme cuja temática faça sentido ao cotidiano do aluno não exclui, como demonstrado no presente artigo, o aprofundamento de um conceito que o faça refletir melhor sobre sua realidade e, além de refletir, possa articular meios de modificá-la e problematiza-la na prática.

Desde pelo menos a LDB (Lei de Diretrizes e Bases da Educação Nacional) de 1996 que o ensino de Filosofia, embora uma única vez mencionada nesse texto, determina a necessidade do aluno dominar os conhecimentos em Filosofia para o exercício da cidadania (art. 36 da referida Lei).No entanto, somente no PCN (Parâmetros Curriculares Nacionais) é que a Filosofia será definida, no âmbito do Ensino Médio, como responsável direta pelo sucesso dos projetos transversais, além do conteúdo próprio de suas grandes áreas. No entanto, o próprio documento que trata das Orientações Curriculares do Ensino Médio para Filosofia (SEB, 2006) admite o hiato 
em termos de amadurecimento como disciplina que a Filosofia teve quando retirada do ensino no regime militar. A essa altura, cabe a nós, professores, não só uma atuação enquanto docentes, mas o papel de desbravadores no amadurecimento do ensino de uma disciplina ausente das grades curriculares por tanto tempo e que reúne em si mesma, aspectos didáticos sui generis: seu conteúdo se constitui também em ferramenta para seu fazer e não se aprende sem exercê-la. Ou seja, tentar definir o que é Filosofia para proceder a seu ensino, já nos adentra em um problema filosófico, o que não acontece com outras disciplinas.

O uso de filmes e produções cinematográficas no ensino de Filosofia (e é possível dizer: no ensino de todas as disciplinas) possibilita inúmeras abordagens, transversalidades e aprofundamentos. A própria linguagem do cinema já se constitui na modernidade do séc. XX a grande Paidéia contemporânea. Despertar o gosto por esse entretenimento e, principalmente promover o conhecimento fora do eixo hollywoodiano, é enriquecer a formação cultural do aluno e permitir que ele adentre diversas outras culturas, assim como identificar realidades próximas. Utilizar dessa experiência para se trabalhar conceitos vistos em sala de aula é um recurso didático poderoso e que tem na transversalidade possível um grande trunfo: ao mesmo tempo em que o tema da disciplina pode ser explorado, pode-se evocar aspectos culturais, históricos, literários e políticos no contexto da produção, proporcionando uma ampliação dessa ferramenta de ensino-aprendizagem, pois qualquer filme retratará uma criação histórica humana sob um determinado modelo social e histórico, certas visões antropológicas, éticas e epistemológicas, portanto, gerando reflexões, educação, formação e impressões de mundo a quem assiste.

Obviamente essa questão do uso do cinema como ferramenta de ensinoaprendizagem esbarra no fato do quanto o próprio professor possui em sua formação o hábito e a reflexão sobre a produção cinematográfica. Nos cursos de Licenciatura em geral já se inclui a assistência a filmes como Atividades Acadêmicas CientíficoCulturais obrigatórias para a feitura de relatórios e construção interpretativa à luz da cadeira de formação. Porém é necessário questionar até que ponto essa atividade ajuda o professor a construir o âmbito de ensino na assistência de filmes.

No exemplo trabalhado no presente artigo, foi importante que a temática do filme abordasse, de alguma forma, o conceito a ser trabalhado. No caso, conceito e temática fílmica convergiram também para a vivência de alunos urbanos que experimentam na pele a realidade retratada na produção e podem problematizar as 
possíveis causas, dinâmicas e campo de ação de sua cidadania na mudança efetiva de sua realidade. Além do próprio conceito de Reificação trabalhado, a problematização da cidade e dos movimentos sociais de protesto convergiu para uma proposta transversal que enriqueceria a discussão e ampliaria o horizonte de análise em direção a uma formação mais crítica dos alunos.

\section{Referências}

BBC BRASIL. O parque que é pivô dos protestos na Turquia. BBC Brasil, [online], 6 Jun. $2013 . \quad$ Disponível em http://www.bbc.com/portuguese/noticias/2013/06/130606_turquia_importancia_gezi_ta ksim_fn - Acesso em 23/06/2015.

BESSA, E. D. A. C. D. Intervenções urbanas e "cidades rebeldes". Revista Brasileira de Ciências Sociais, São Paulo, v. 29, n. 85, p. 213-215, jun. 2014. Acesso em 15/06/2015 - Disponível em http://dx.doi.org/10.1590/S0102-69092014000200015.

CUNHA, J. M. P. D. Migração e urbanização no Brasil - alguns desafios metodológicos para análise. São Paulo em Perspectiva, [online], v. 19, n. 4, p. 3-20, 2005. Disponível em http://dx.doi.org/10.1590/S0102-88392005000400001 - Acesso em 23/06/2015.

GAETE, C. M. Mapa da urbanização no mundo entre 1950 e 2030. ArchDaily Brasil, [online], 09 Mar 2015. Trad. Julia Brant. Disponível em http://www.archdaily.com.br/br/763172/mapas-a-urbanizacao-no-mundo-entre-1950-e2030 - Acesso em 23/06/2015.

HARVEY, D. A Liberdade da Cidade. In: DIVERSOS Cidades Rebeldes - Passe Livre e as Manifestações que Tomaram as Ruas do Brasil. São Paulo: Boitempo Editoral; Carta Maior, 2013. p. 34-44.

HERVEY, D. A Crise da Urbanização Planetária. Blog da BOITEMPO, [online], 10 Jan 2015. Disponível em http://blogdaboitempo.com.br/2015/01/10/david-harvey-acrise-da-urbanizacao-planetaria/ - Acesso em 26/06/2015.

LUKÁCS, G. História e Consciência de Classe. Tradução de Rodnei Nascimento. São Paulo: Martins Fontes, 2003.

MEDIANERAS - Buenos Aires na Era do Amor Virtual. Direção: Gustavo Taretto. [S.1.]: [s.n.]. 2011. $95 \mathrm{~min}$.

PINASSE, M. O.; LESSA, S. György Lukács: uma breve biografia. In: PINASSE, M. O.; LESSA, S. Lukács e a atualidade do marxismo. São Paulo: Boitempo Editorial, 2002.

SEB. Orientações Curriculares para o Ensino Médio. Brasília: MEC - Ministério da Educação e SEB - Secretaria da Educação Básica, v. 3 (Ciências Humanas e suas Tecnologias), 2006. 